Products and Services In Practice is provided to readers using text and images from the manufacturer, supplier or distributor and does not imply endorsement by $B D J$ In Practice. Normal and prudent research should be exercised before purchase or use of any product mentioned.

Please send product and services news through to David Westgarth, BDJ In Practice via: David.Westgarth@bda.org

\section{Don't miss out!}

This month's British Orthodontic Conference being held at the SEC in Glasgow between 19-21 September promises something for everyone - and as it takes place next week, time is fast running out to book your place.

Highlights of the programme include:

$\rightarrow$ Acclaimed IVF pioneer Professor Robert Winston delivering a keynote presentation on Thursday 19 September asking, 'Can we achieve happiness?'

$\rightarrow$ The prestigious Northcroft memorial lecture presented by Professor Greg Huang from Washington State University on 'Results from the NDPBRN Adult Anterior Open-bite Study'

$\rightarrow$ Jay Bowman from the US delivering two sessions - 'Uno, Dos, Tres: All miniscrews in one place (mostly); and 'Drastic Plastic: Improving the predictability of clear aligners'

$\rightarrow$ Peter Miles from Australia presenting on 'The agony and ecstasy of Invisalign'

$\rightarrow$ Former MP Lembit Opik alongside Michael Millwaters and Pratik Sharma discussing his orthognathic case and experience.

There is also a parallel session on 'Driving Your Private Practice' with many great speakers including Chris Barrow, Magali Mujagic, Claire Nightingale and Peter Huntley. 2019 marks the $25^{\text {th }}$ anniversary of the British Orthodontic Society and there will be much celebration at the conference.

A combined team rate is on offer too so that the whole team can come along, learn a lot and have fun.

For a full speaker programme, please visit https://www.bos.org.uk/BOC-

Glasgow-2019-Programme

To make sure that you don't miss out, to book please visit https://www.bos.org.uk/ BOC-Glasgow-2019

\section{Easily obtain hard data}

Numbers provide certainty. A clinician

may offer an opinion, but in an era where people are more likely than ever to question experts, being able to present hard data can help foster certainty and build trust among patients.

The Osstell Beacon from W\&H provides precise ISQ measurements of implant stability, an easily understood value ranging from 1 to 100. The Osstell Beacon can expediently produce a reading that you can share as part of ongoing patient education - helping to make patients feel included and preventing uncertainty.

Find out more about how the Osstell Beacon can help you and your patients by contacting W\&H on 01727874990 or emailoffice.uk@wh.com.
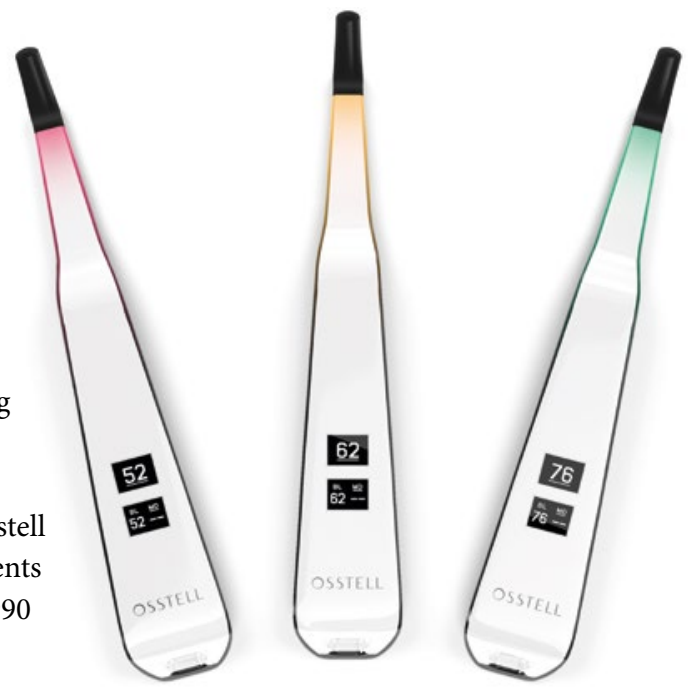

\section{Down to the last detail}

Dentistry requires shrewd attention to detail in order to perform accurate diagnostics. This is crucial in the case of dental caries treatment, which is why Nuview supplies advanced dental microscopes from leading manufacturer, Carl Zeiss.

Modern solutions like the EXTARO 300 facilitate the delivery of high-quality care by offering a unique combination of breakthrough visualisation modes.
This includes the innovative Fluorescence Mode, which enables clinicians to efficiently visualise and repair caries-infected fillings. The EXTARO 300 also saves valuable time in practice, as there is no need to interrupt workflow for visual support.

Contact Nuview for further details on 01453 872266, email info@nuview-ltd.com, visit www.nuview.co or 'like' Nuview on Facebook.

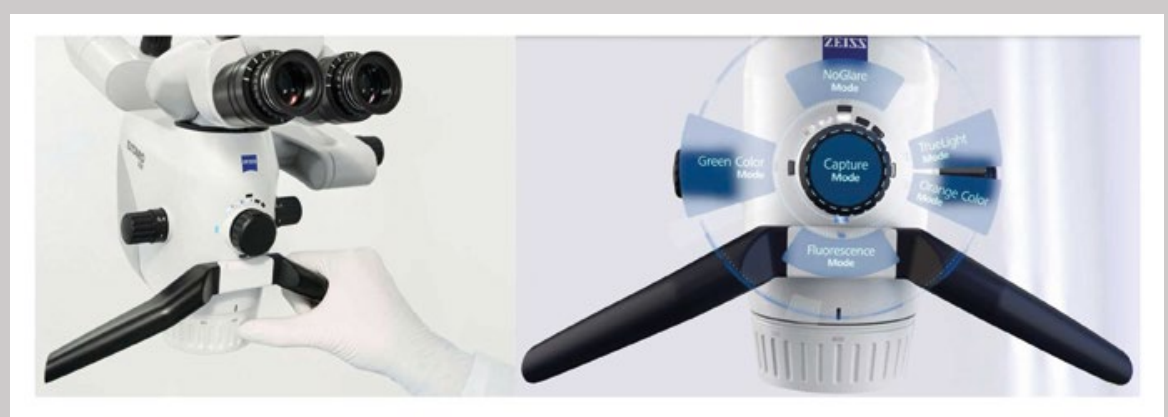

